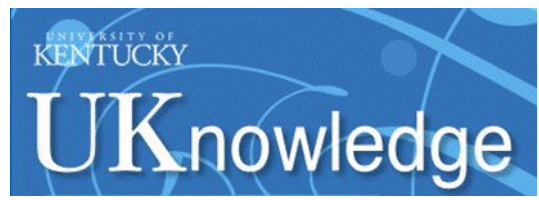

University of Kentucky

UKnowledge

Biosystems and Agricultural Engineering Faculty Publications

\title{
Object Detection for Agricultural and Construction Environments Using an Ultrasonic Sensor
}

\author{
Joseph S. Dvorak \\ University of Kentucky, joe.dvorak@uky.edu \\ Marvin L. Stone \\ Oklahoma State University \\ Kelvin P. Self \\ Charles Machine Works, Inc.
}

Follow this and additional works at: https://uknowledge.uky.edu/bae_facpub

Part of the Bioresource and Agricultural Engineering Commons, and the Construction Engineering and Management Commons

Right click to open a feedback form in a new tab to let us know how this document benefits you.

\section{Repository Citation}

Dvorak, Joseph S.; Stone, Marvin L.; and Self, Kelvin P., "Object Detection for Agricultural and Construction Environments Using an Ultrasonic Sensor" (2016). Biosystems and Agricultural Engineering Faculty Publications. 44.

https://uknowledge.uky.edu/bae_facpub/44

This Article is brought to you for free and open access by the Biosystems and Agricultural Engineering at UKnowledge. It has been accepted for inclusion in Biosystems and Agricultural Engineering Faculty Publications by an authorized administrator of UKnowledge. For more information, please contact UKnowledge@lsv.uky.edu. 


\section{Object Detection for Agricultural and Construction Environments Using an Ultrasonic Sensor}

Digital Object Identifier (DOI)

https://doi.org/10.13031/jash.22.11260

\section{Notes/Citation Information}

Published in Journal of Agricultural Safety and Health, v. 22, issue 2, p. 107-119.

(C) 2016 ASABE

The copyright holder has granted the permission for posting the article here. 


\title{
Object Detection for Agricultural and Construction Environments Using an Ultrasonic Sensor
}

\author{
J. S. Dvorak, M. L. Stone, K. P. Self
}

ABSTRACT. This study tested an ultrasonic sensor's ability to detect several objects commonly encountered in outdoor agricultural or construction environments: a water jug, a sheet of oriented strand board (OSB), a metal fence post, a human model, a wooden fence post, a Dracaena plant, a juniper plant, and a dog model. Tests were performed with each target object at distances from 0.01 to $3 \mathrm{~m}$. Five tests were performed with each object at each location, and the sensor's ability to detect the object during each test was categorized as "undetected," "intermittent," "incorrect distance," or "good." Rigid objects that presented a larger surface area to the sensor, such as the water jug and OSB, were better detected than objects with a softer surface texture, which were occasionally not detected as the distance approached $3 \mathrm{~m}$. Objects with extremely soft surface texture, such as the dog model, could be undetected at almost any distance from the sensor. The results of this testing should help designers of future systems for outdoor environments, as the target objects tested can be found in nearly any agricultural or construction environment.

Keywords. Human presence, Obstacle detection, Safety, Sensors, Ultrasonic.

$\mathrm{M}$ any future developments in outdoor mobile machinery (including both construction and agriculture) will rely on the ability of sensors to properly detect desired target objects while not detecting non-target objects. The difference between target objects and non-target objects will vary widely and depend on the task the machine is performing and the operating environment. Ultrasonic sensors are often considered for use in agricultural and construction applications because they are robust and relatively low-cost (Andújar et al., 2011). In its most basic form, an ultrasonic sensor emits a pulse of ultrasonic waves, which contact an object and are then reflected back to a receiver. Although some researchers have used the characteristics of the reflected wave for identification of the properties of the object that reflected the waves (Aziz et al., 2004), most uses of ultrasonic sensors rely on the time-of-flight principle to determine the distance to the object that reflected the waves.

Although ultrasonic sensors present a useful option as a sensing technology, they also

Submitted for review in March 2015 as manuscript number JASH 11260; approved for publication by the Ergonomics, Safety, \& Health Community of ASABE in December 2015.

The authors are Joseph S. Dvorak, ASABE Member, Assistant Professor, Department of Biosystems and Agricultural Engineering, University of Kentucky, Lexington, Kentucky; Marvin L. Stone, ASABE Fellow, Regents Professor, Department of Biosystems and Agricultural Engineering, Oklahoma State University, Stillwater, Oklahoma; Kelvin P. Self, ASABE Member, R\&D Project Manager, Charles Machine Works, Inc., Perry, Oklahoma. Corresponding author: Joseph S. Dvorak, 128 C.E. Barnhart Building, University of Kentucky, Lexington, KY 40546-0276; phone: 859-257-5658; e-mail: joe.dvorak@uky.edu.

Journal of Agricultural Safety and Health 
have some important limitations. One of the primary issues with ultrasonic sensors is that the characteristics of the target can degrade the sensor's ability to provide even the most basic measurement: the distance to the target. The shape and composition of an object determine the strength of its reflected wave. A complex shape will produce many reflections at different angles, which will then create a complex signal when summed at the receiver. Coarse, irregular surfaces will diffuse and reflect the sound wave in many directions, leaving little to return to the sensor (Shirley, 1989). Textured objects, fur, or wool can absorb much of the sound wave so that very little is reflected back to the sensor (Shirley, 1989; Turner and Austin, 2000). Higher-frequency sound waves are better for detecting these types of targets and can distinguish smaller targets as well (Massa, 1999; Shirley, 1989). However, sound waves at higher frequencies experience greater attenuation in the atmosphere, resulting in a shorter detection distance (Massa, 1999). Orientation is also important, since a large flat target not perpendicular to the sensor will reflect much of the sound wave in a direction away from the sensor (Shirley, 1989). Many of these issues were considered by O'Sullivan (1986), who performed basic early investigations with ultrasonic sensors for agricultural purposes to provide insight into their ability to respond to various surfaces.

Ultrasonic sensors were used by Guo et al. (2002) in the development of a safety system for detecting approaching humans near tractors. Other tests of ultrasonic sensors have specifically investigated the effect of various environmental factors (Jeon et al., 2011) or sensor interferences (Escolà et al., 2011). However, these tests have all focused on detection of a single type of surface and do not consider how the sensor would respond to surfaces other than the one of interest in the study. One of the few studies in which ultrasonic sensors were used for general object differentiation in an outdoor environment was performed by Leidenfrost et al. (2013). They used an ultrasonic sensor in combination with a vision system for general obstacle detection around an autonomous vehicle.

Although only a few ultrasonic sensor studies have focused on object differentiation and environmental factors that could affect sensor operation, such research has been extensively considered for other sensor types. In outdoor environments, these projects have often attempted to help an operator control larger equipment or provide a degree of autonomy to agricultural operations (Keicher and Seufert, 2000). The ability to reliably detect the presence of humans around agricultural equipment was tested by Shutske et al. (2001) using microwave and passive infrared sensors, and these sensors were combined with radar by Venem et al. (2006). Buck (1991) investigated the ability of a sensor to identify human presence using a capacitive proximity sensor at close range. Others (Wei et al., 2005; Yang and Noguchi, 2012) have used vision systems to detect humans around agricultural machinery. Thermal cameras have been used to detect animals hidden in forage crops (Steen et al., 2012). LIDAR systems have also been studied to determine their applicability to detect and classify objects in an agricultural setting (Doerr et al., 2013; Kise et al., 2005). In the conclusion to their article on human detection with a vision system, Yang and Noguchi (2012) point out that it is vital that further research be conducted to identify how the sensors respond to different obstacles in different operating conditions.

As agricultural operations become more autonomous (whether because there is no driver or simply because the end of the implement is too far from the cab to reliably control), it will be less possible to rely on a human operator to ensure that the surface detect- 
ed by an ultrasonic sensor is the one of interest for the operation. Therefore, it will be necessary to consider how the sensor will respond to any of the many types of objects that could be present in the work environment. To provide some of this information, this study focused on the ability of a single ultrasonic sensor to detect several objects commonly found in outdoor agricultural or construction environments in a best-case scenario. Certain target types, such as people and animals, will be important to designers of safety systems. Targets such as fence posts will be important for engineers working on obstacle detection for vehicle navigation. Other targets, such as different types of plants, could be unimportant and represent interference (e.g., navigation through a pasture or uncut hay meadow) or could be vital to the operation (e.g., a forage cutter detecting cut and uncut crop). It will be up to the designer of a specific system to determine which target objects are important and to test any safety system in its expected operating environment. The target objects considered in this study represent classes of objects that can appear in almost any agricultural or construction setting, so designers of future systems need to consider how the sensor will respond to these objects. Therefore, the objective of this study was to identify how an ultrasonic sensor will respond to these target objects: a water jug, a sheet of oriented strand board (OSB), a metal fence post, a human model, a wooden fence post, a Dracaena plant, a juniper plant, and a dog model. This study also included a brief consideration of interferences that could affect sensor operation.

\section{Methods and Materials}

\section{Ultrasonic Sensor}

The ultrasonic sensor used in this experiment was a Senix Ultra-S-BP (Senix Corp., Hinesburg, Vt.). The nominal beam angle for this sensor is $15^{\circ}$. The sensor's gain and minimum range were adjusted so that the sensor could accurately respond to an object as close as $7 \mathrm{~cm}$ from the sensor. A higher gain caused the sensor to detect only itself and produced a continuous detection at the minimum distance regardless of whether an object was present or not. A lower gain interfered with the sensor's ability to detect objects at the maximum distance used in this experiment, which was $3 \mathrm{~m}$. The gain of the sensor was thus set as high as possible while not detecting itself. The sensor was placed on a table (approx. $0.75 \mathrm{~m}$ high) during testing to elevate it above the floor, prevent interference from the floor, and locate it at a height that best allowed the sensor to detect the range of objects evaluated. Using these settings with an RS-232 connection to a computer running the Senix WinSpan program, the sensor provided a distance estimate approximately every $160 \mathrm{~ms}$. During preliminary testing, it became evident that four different response types could be expected from the sensor. For a well-detected target object, the sensor provided consistent, accurate distances to the object. An object could also be completely undetected by the sensor, in which case the sensor did not provide any distance estimates. Objects generally transitioned from well-detected to undetected as they moved farther away from the sensor. During this transition, the sensor often went through an intermittent phase in which nearly every other sample alternated between an accurate distance and no detection. Finally, the sensor could also provide an inaccurate distance estimate under certain circumstances.

\section{Target Objects}

Target objects were selected to represent objects that can be commonly found in out- 
door settings where agricultural or construction equipment is often operated. The target objects used to test the sensor's operation were a water jug, a sheet of OSB, a metal fence post, a human model, a wooden fence post, a Dracaena plant, a juniper plant, and a dog model. These objects are not meant to exhaustively represent every object present in these environments but were instead selected to have a variety of characteristics to test the sensor's response to objects with those characteristics.

The water jug (model 1692, Gott Mfg. Co., Winfield, Kans.) had a diameter of $25 \mathrm{~cm}$ and was $40 \mathrm{~cm}$ tall (fig. 1). Its $7.5 \mathrm{~L}$ capacity was filled with room temperature water. Although water jugs are not often encountered in open agricultural fields, they can be found in areas where humans are working near machinery, such as around barns or in construction sites. The water jug is also similar to many other containers (toolboxes, buckets, crates) that are often found in similar environments in that it is a small, rigid, compact, manufactured object. The water jug was supported on plastic crates so that the center of the jug was located at the same height as the ultrasonic sensor during testing.

The sheet of OSB was $1.2 \mathrm{~m} \times 1.2 \mathrm{~m} \times 1.25 \mathrm{~cm}$. It was held upright by a wooden stand. Figure 2 is a photograph of the OSB target object in which the support stand is visible. During testing, the sheet of OSB was oriented so that the side opposite the stand was perpendicular to the sensor. Thus, this target object appeared to the sensor as a large flat object. Similar flat boards are used for various purposes in construction, so it would not be unusual for a construction vehicle to be operating near such a surface. To a lesser extent, this target object also simulated the characteristics of walls or solid fences that can be found in many places in both agriculture and construction environments. Such walls and fences are often not completely smooth or made of the same material as this target object, but they will still present a large relatively flat surface to the sensor.

The metal fence post (fig. 3) was a metal post of the type used in the construction of

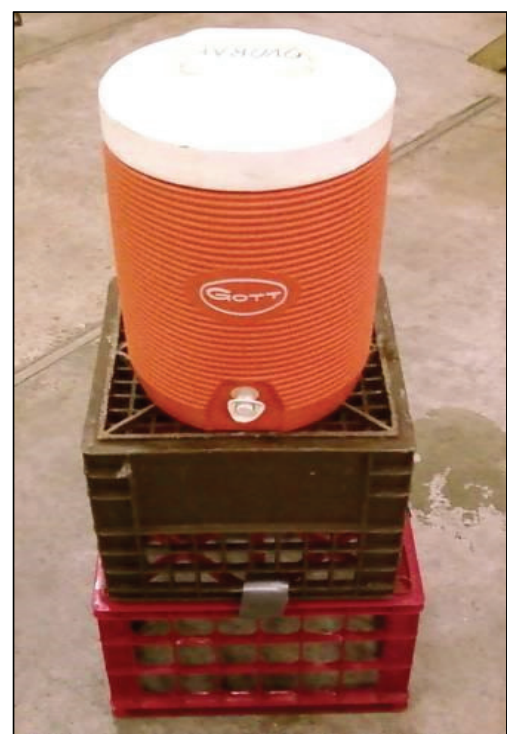

Figure 1. Water jug target object.

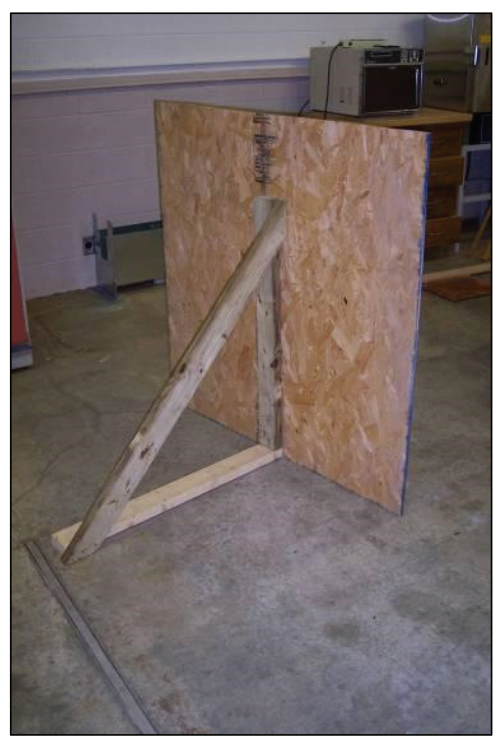

Figure 2. Oriented strand board (OSB) target object (shown from behind so that stand is visible). 
fences around agricultural fields. The post was welded to a small metal plate to allow it to stand freely. The post was " $T$ " shaped in cross-section, with the top and center of the "T" both $3 \mathrm{~cm}$ in length. The metal fence post was $197 \mathrm{~cm}$ tall. This target object was selected to represent the metal posts that are often found in outdoor environments to support fencing, signs, or other objects.

The human model used for testing was a more complicated object. A model for a human was used rather than actual human test subjects to reduce concerns about human safety and privacy, to provide a consistent target object over time, and to ensure compliance with regulatory requirements. A picture of the human model as it was tested is shown in figure 4. Figure 6 is a computer drawing of the structure of the model, since clothing obscures much of the structure in figure 4 . The human model consisted of a human form made of polyvinyl chloride (PVC) and a metal stand to support the model. The stand was attached to a wheeled metal cart to allow the model to be moved easily.

The torso was made of PVC sheets, and the rest of the body was made with PVC tubing. Silicone caulk was used to seal the corners of the torso. The arms, legs, and neck were PVC tubing with an outside diameter of $89 \mathrm{~mm}$ and an inside diameter of $78 \mathrm{~mm}$ (nominally 3 in., schedule 40 PVC tubing). The joints for the shoulders and feet were $90^{\circ}$ PVC elbows. Flanges connected all the tubing to the torso, and the arms and feet were capped at the ends. The head was constructed of PVC tubing with an outside diameter of $170 \mathrm{~mm}$ and an inside diameter of $154 \mathrm{~mm}$ (nominally 6 in., schedule 40 PVC tubing). Two reducers were required to connect the head to the torso. The short piece of tubing connecting the reducers to the torso had an outside diameter of $118.4 \mathrm{~mm}$ and an inside diameter of $102 \mathrm{~mm}$ (nominally $4 \mathrm{in}$., schedule $40 \mathrm{PVC}$ tubing). The top of the head was machined so that a drain waste vent (DWV) cap with an outside diameter of $170 \mathrm{~mm}$ and an inside diameter of $160 \mathrm{~mm}$ slipped freely over the top of the head.

The human model was filled with water during testing. Although the water was not expected to have an impact on the ultrasonic sensor, this model was also used for testing other sensors that relied more heavily on the water content for detection. Fittings were attached to the caps on the feet so that warm water could be pumped through internal piping within the model to maintain its temperature close to body temperature. This temperature control was not expected to play a significant role in the ability of the ultrasonic sensor to detect the human model; however, as the human model was also used to test other sensors, this capability was built into the model. Finally, the human model was clothed in a t-shirt and jeans by cutting the backs of the clothes and fastening the clothes around the human model with safety pins. During testing, the human model was oriented so that it was facing the sensor. This provided the largest surface area to the sensor and represented the best expected detection scenario.

The wooden fence post (fig. 5) was a round wooden post sold for use in constructing agricultural fences. It was $7.6 \mathrm{~cm}$ in diameter and $170 \mathrm{~cm}$ tall. Like the metal fence post, the wooden fence post was selected because it was similar to the wooden posts that are commonly used in outdoor environments for fence construction and to support other objects. The sensor tests included two types of fence posts (wooden and metal) because both types are commonly used, they were made of different materials with different properties, and they represented two different target geometries. 

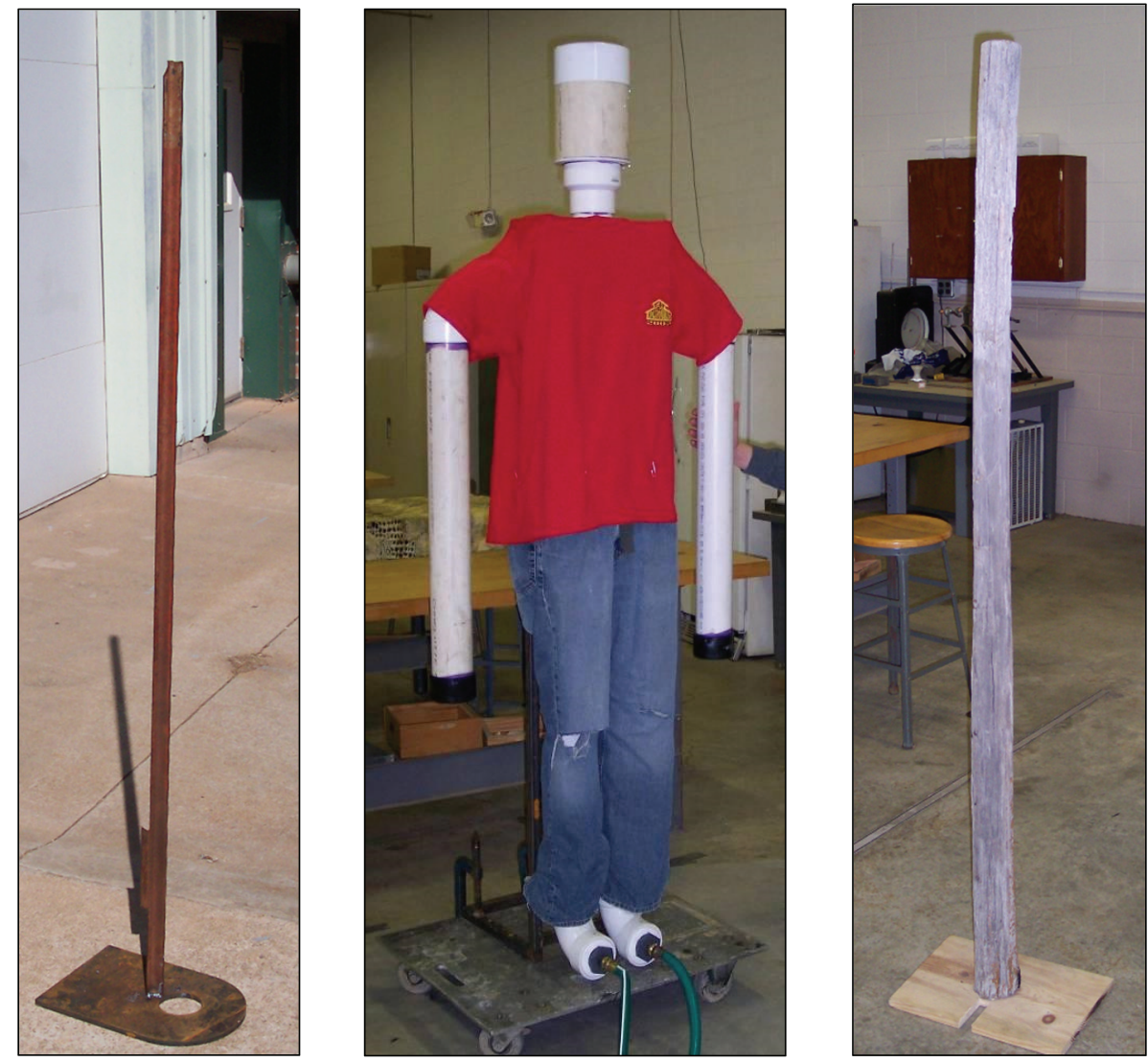

Figure 3. Metal fence post Figure 4. Human model target object. Figure 5. Wooden fence post target object. target object.

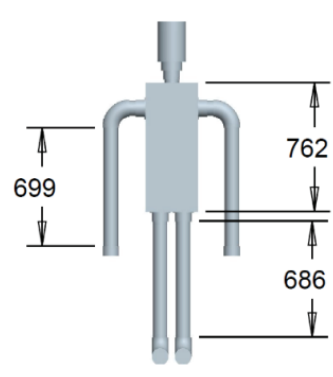

(a)

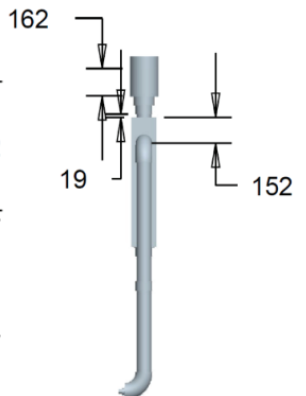

(b)

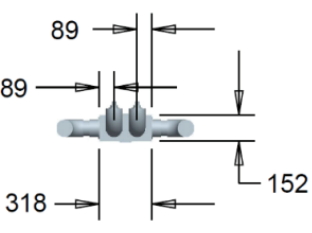

(c)

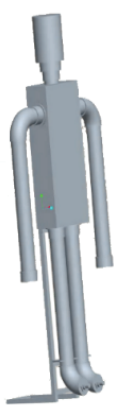

(d)

Figure 6. Computer drawing of human model target object: (a) front view, (b) side view, (c) bottom view, and (d) angled view (all dimensions are $\mathrm{mm}$ ). 
The plant target object (fig. 7) was of the genus Dracaena. The exact species was not available when it was purchased; however, it had characteristics matching the marginata species, which is also listed as Dracaena reflexa var. angustifolia. It had long flexible strap-like leaves. The plant was rooted in potting soil in a container $20 \mathrm{~cm}$ high with a volume of $6.3 \mathrm{~L}$. Excluding the container, the plant was $60 \mathrm{~cm}$ tall and $60 \mathrm{~cm}$ in diameter. Although plants of the genus Dracaena are most often found in outdoor environments in Africa, southern Asia, and Central America, the long flexible leaves resemble the structure of many other plants, such as grasses or crop plants that are found worldwide. Unlike many grasses or crop plants, the Dracaena plant target object had been developed as a houseplant. Thus, it was easy to maintain during testing and was not rapidly developing or growing, which would have prevented its use as a consistent test object. The Dracaena plant was placed on crates during testing to align the center of the leafy part of the plant with the sensor.

The juniper (fig. 8) was a Youngstown Andorra juniper (Juniperus horizontalis 'Andorra Youngstown') in a 9.7 L container filled with potting soil. Excluding the container, the juniper was $40 \mathrm{~cm}$ tall and $60 \mathrm{~cm}$ in diameter. It was also placed on plastic crates during testing so that the leafy part of the plant was at the same height as the sensor. This target object with its smaller, denser leaf structure was selected to represent evergreens and other similar plants that are found in many agricultural and construction environments.

The final target object was a model of a dog. As with the human model, a model was used for this testing to ensure consistent results, allow adequate control of the object position, and alleviate concerns over animal welfare in testing. A picture of the dog model as tested is shown in figure 9. The body of the dog model was a length of PVC tube with an internal diameter of $154 \mathrm{~mm}$ and an outside diameter of $170 \mathrm{~mm}$. This tube was capped on both ends, and fittings were added to allow filling with water and circulation of warm water through the model during testing. A computer drawing of these PVC components is shown in figure 10. The PVC tube was placed on plastic crates, and the PVC tube and

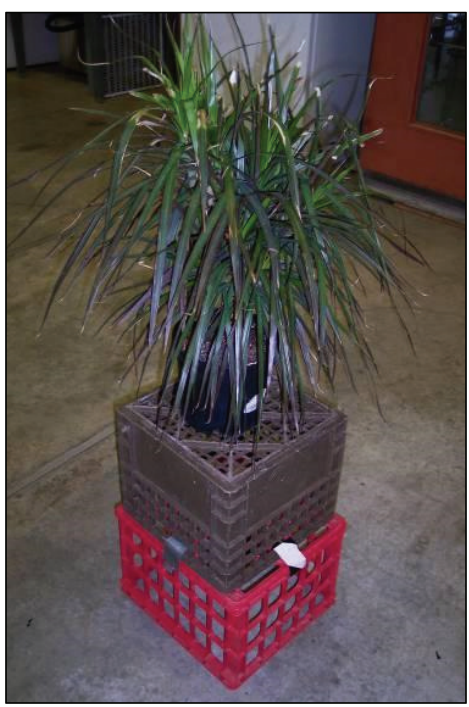

Figure 7. Dracaena plant target object.

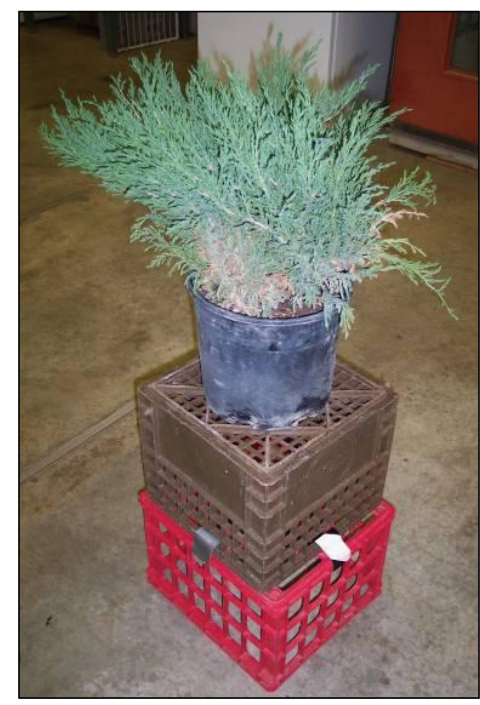

Figure 8. Juniper plant target object. 


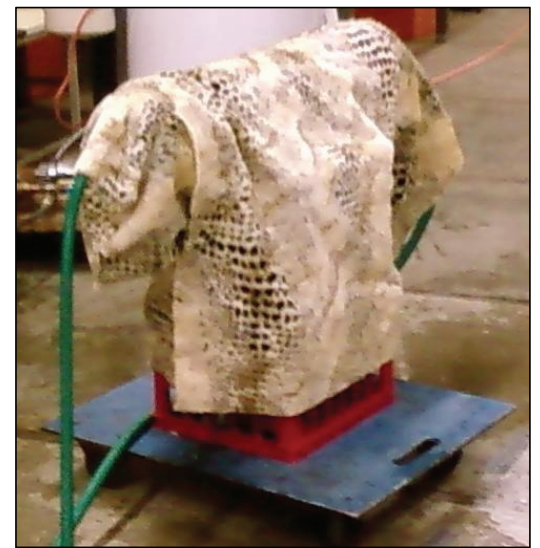

(a)

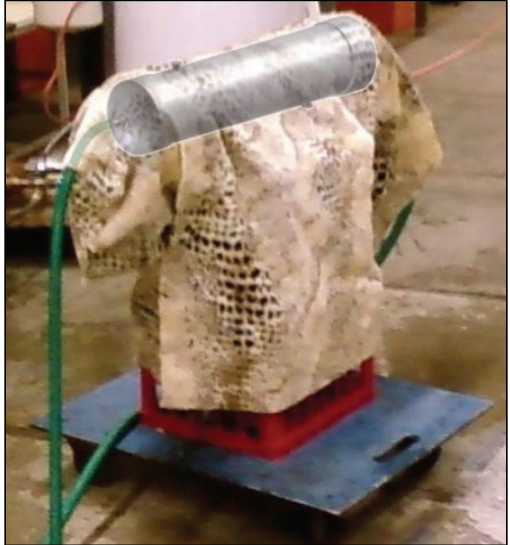

(b)

Figure 9. Dog model target object (a) as tested and (b) with external surface rendered transparent to reveal placement of the internal body.

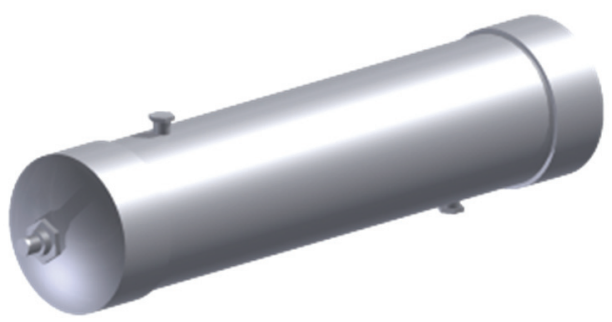

Figure 10. Computer drawing of the internal body of the dog model target.

plastic crates were wrapped in faux fur with a nap depth of $10 \mathrm{~mm}$. As with the plants, the height and orientation of the dog model during testing was such that the largest part of the model was the same height as the sensor and faced toward the sensor. The overall size and height of the dog model approximated that of a large dog.

\section{Test Procedure}

The spatial sensitivity of the sensor was determined by placing a target object at 14 different locations and recording the sensor's response to the object at each location. The 14 locations were all centered in front of the sensor and aligned with the reference axis of the sensor's beam at the following distances from the sensor: $0.025 \mathrm{~m}, 0.05 \mathrm{~m}$, $0.075 \mathrm{~m}, 0.1 \mathrm{~m}, 0.2 \mathrm{~m}, 0.3 \mathrm{~m}, 0.4 \mathrm{~m}, 0.5 \mathrm{~m}, 0.75 \mathrm{~m}, 1 \mathrm{~m}, 1.5 \mathrm{~m}, 2 \mathrm{~m}, 2.5 \mathrm{~m}$, and $3 \mathrm{~m}$. When placing the target object at a given location, the target surface closest to the sensor was used to determine the distance. Once the object was in place, the sensor's response was recorded for at least $1 \mathrm{~s}$, which corresponded to at least six samples (individual sensor readings) at each location for each target object. The target object was then moved to the next location. Each target object was cycled through all locations five times before moving to the next target object. Thus, there were five separate tests (with each test consisting of at least six individual sensor readings) at each location for each target object. The data from each of these five tests were processed individually and categorized into 
one of four different response types.

If the sensor reported that there was no object present for an entire test, the response to the target object was categorized as "undetected." If some samples in a test indicated an object but other samples in the same test indicated no object present, the response was categorized as "intermittent," as the target was only detected intermittently. If the object was consistently detected but the average distance was either less than $75 \%$ or greater than $125 \%$ of the actual distance, the response was categorized as "incorrect distance." If the object was consistently detected at an average distance between $75 \%$ and $125 \%$ of the actual distance, the response was categorized as "good." Thus, a "good" detection is a condition in which a designer could expect the sensor to operate consistently well. An "intermittent" or "incorrect distance" detection indicates that detection could be expected, but a designer would need to carefully consider the data provided. In these cases, a sensor array or special filtering may be necessary for reliable results. Finally, an "undetected" result indicates that the sensor by itself would not be reliable.

A limited amount of testing was also done to investigate the effect of various interferences on the sensor's ability to detect a target object. In all of these tests, the target object was the human model. The same testing locations and procedures were used, but the target object was only cycled through each location once for each interference test. The following interferences were tested: mounting the sensor on a Ditch Witch trencher (model 6510, Charles Machine Works, Inc., Perry, Okla.) and three tests with the Dracaena plant located in front of the sensor at distances of $0.1,1.5$, and $3 \mathrm{~m}$. The test with the trencher was done to determine whether mounting the sensor on mobile machinery rather than on a table in a laboratory would affect its operation. The trencher was similar in size to the small tractors used in many construction and agricultural tasks, and it was stationary and off during testing. The interference testing with the Dracaena plant was done to determine the extent to which the plant's presence would reduce the sensitivity of the sensor to the target object. Growing plants are often found in agricultural and construction settings. For some ultrasonic sensor applications, it may be necessary to detect other objects when plants are also in the detection region.

Preliminary testing was also performed with the wooden post target object at a variety of offsets from the reference axis of the sensor's beam. Results were as expected, with detection only occurring within the narrow $15^{\circ}$ beam angle of the sensor. Given the narrow detection angle, all further tests with other target objects were performed on the sensor's reference beam axis to determine best-case detection. Clearly, for any type of area coverage, an array of ultrasonic sensors would be necessary, and designers must consider how to structure the array to appropriately cover the region of interest.

\section{Results}

\section{Target Object Testing}

The results of the experiment with target objects are displayed in table 1. For each target object, each distance is coded with gray shading. No shading indicates that the detection was "good" (consistent and accurate) for all tests with that object and distance. Light shading indicates that either the distance was reported incorrectly or the detection was intermittent in at least one test with that object and distance. Dark shading indicates that the object was undetected in at least one test with that object and distance. 
Table 1. Percent detection in each category for each object at each distance. Shading indicates detection type.

\begin{tabular}{|c|c|c|c|c|c|c|c|c|c|c|c|c|c|c|c|}
\hline \multirow{2}{*}{$\begin{array}{l}\text { Target } \\
\text { Object }\end{array}$} & \multirow{2}{*}{$\begin{array}{l}\text { Detection } \\
\text { Type }\end{array}$} & \multicolumn{14}{|c|}{ Distance $(\mathrm{m})$} \\
\hline & & 0.025 & 0.05 & 0.075 & 0.1 & 0.2 & 0.3 & 0.4 & 0.5 & 0.75 & 1 & 1.5 & 2 & 2.5 & 3 \\
\hline \multirow{4}{*}{$\begin{array}{c}\text { Water } \\
\text { jug }\end{array}$} & Good & 0 & 0 & 100 & 100 & 100 & 100 & 100 & 100 & 100 & 100 & 100 & 100 & 100 & 100 \\
\hline & Intermittent & 0 & 0 & 0 & 0 & 0 & 0 & 0 & 0 & 0 & 0 & 0 & 0 & 0 & 0 \\
\hline & Incorrect & 100 & 100 & 0 & 0 & 0 & 0 & 0 & 0 & 0 & 0 & 0 & 0 & 0 & 0 \\
\hline & Undetected & 0 & 0 & 0 & 0 & 0 & 0 & 0 & 0 & 0 & 0 & 0 & 0 & 0 & 0 \\
\hline \multirow{4}{*}{ OSB } & Good & 0 & 0 & 80 & 100 & 100 & 100 & 100 & 100 & 100 & 100 & 100 & 100 & 100 & 100 \\
\hline & Intermittent & 0 & 0 & 0 & 0 & 0 & 0 & 0 & 0 & 0 & 0 & 0 & 0 & 0 & 0 \\
\hline & Incorrect & 100 & 100 & 20 & 0 & 0 & 0 & 0 & 0 & 0 & 0 & 0 & 0 & 0 & 0 \\
\hline & Undetected & 0 & 0 & 0 & 0 & 0 & 0 & 0 & 0 & 0 & 0 & 0 & 0 & 0 & 0 \\
\hline \multirow{4}{*}{$\begin{array}{c}\text { Metal } \\
\text { fence } \\
\text { post }\end{array}$} & Good & 0 & 0 & 60 & 100 & 100 & 100 & 100 & 100 & 100 & 100 & 100 & 80 & 100 & 100 \\
\hline & Intermittent & 0 & 0 & 0 & 0 & 0 & 0 & 0 & 0 & 0 & 0 & 0 & 20 & 0 & 0 \\
\hline & Incorrect & 100 & 100 & 40 & 0 & 0 & 0 & 0 & 0 & 0 & 0 & 0 & 0 & 0 & 0 \\
\hline & Undetected & 0 & 0 & 0 & 0 & 0 & 0 & 0 & 0 & 0 & 0 & 0 & 0 & 0 & 0 \\
\hline \multirow{4}{*}{$\begin{array}{c}\text { Human } \\
\text { model }\end{array}$} & Good & 0 & 0 & 20 & 60 & 80 & 100 & 100 & 100 & 100 & 100 & 100 & 100 & 100 & 100 \\
\hline & Intermittent & 0 & 0 & 0 & 0 & 0 & 0 & 0 & 0 & 0 & 0 & 0 & 0 & 0 & 0 \\
\hline & Incorrect & 100 & 100 & 80 & 40 & 20 & 0 & 0 & 0 & 0 & 0 & 0 & 0 & 0 & 0 \\
\hline & Undetected & 0 & 0 & 0 & 0 & 0 & 0 & 0 & 0 & 0 & 0 & 0 & 0 & 0 & 0 \\
\hline \multirow{4}{*}{$\begin{array}{l}\text { Wooden } \\
\text { fence } \\
\text { post }\end{array}$} & Good & 0 & 0 & 0 & 100 & 100 & 100 & 100 & 100 & 100 & 100 & 100 & 100 & 60 & 0 \\
\hline & Intermittent & 0 & 0 & 0 & 0 & 0 & 0 & 0 & 0 & 0 & 0 & 0 & 0 & 40 & 40 \\
\hline & Incorrect & 100 & 100 & 100 & 0 & 0 & 0 & 0 & 0 & 0 & 0 & 0 & 0 & 0 & 0 \\
\hline & Undetected & 0 & 0 & 0 & 0 & 0 & 0 & 0 & 0 & 0 & 0 & 0 & 0 & 0 & 60 \\
\hline \multirow{4}{*}{$\begin{array}{c}\text { Dracaena } \\
\text { plant }\end{array}$} & Good & 0 & 0 & 20 & 100 & 60 & 100 & 100 & 100 & 100 & 100 & 100 & 100 & 20 & 40 \\
\hline & Intermittent & 0 & 0 & 0 & 0 & 0 & 0 & 0 & 0 & 0 & 0 & 0 & 0 & 40 & 0 \\
\hline & Incorrect & 100 & 100 & 80 & 0 & 40 & 0 & 0 & 0 & 0 & 0 & 0 & 0 & 0 & 0 \\
\hline & Undetected & 0 & 0 & 0 & 0 & 0 & 0 & 0 & 0 & 0 & 0 & 0 & 0 & 40 & 60 \\
\hline \multirow{4}{*}{$\begin{array}{l}\text { Juniper } \\
\text { plant }\end{array}$} & Good & 0 & 0 & 100 & 100 & 100 & 100 & 100 & 100 & 100 & 100 & 100 & 100 & 20 & 0 \\
\hline & Intermittent & 0 & 0 & 0 & 0 & 0 & 0 & 0 & 0 & 0 & 0 & 0 & 0 & 20 & 0 \\
\hline & Incorrect & 100 & 100 & 0 & 0 & 0 & 0 & 0 & 0 & 0 & 0 & 0 & 0 & 0 & 0 \\
\hline & Undetected & 0 & 0 & 0 & 0 & 0 & 0 & 0 & 0 & 0 & 0 & 0 & 0 & 60 & 100 \\
\hline \multirow{4}{*}{$\begin{array}{l}\text { Dog } \\
\text { model }\end{array}$} & Good & 0 & 0 & 20 & 80 & 20 & 80 & 100 & 60 & 60 & 40 & 20 & 0 & 0 & 0 \\
\hline & Intermittent & 0 & 0 & 0 & 0 & 0 & 0 & 0 & 0 & 0 & 0 & 0 & 0 & 0 & 0 \\
\hline & Incorrect & 80 & 100 & 60 & 20 & 40 & 0 & 0 & 0 & 0 & 0 & 0 & 0 & 0 & 0 \\
\hline & Undetected & 20 & 0 & 20 & 0 & 40 & 20 & 0 & 40 & 40 & 60 & 80 & 100 & 100 & 100 \\
\hline
\end{tabular}

For all objects (except the dog model), distances less than $0.075 \mathrm{~m}$ were reported as $0.07 \mathrm{~m}$. This inaccuracy was expected, as the minimum detection distance for the sensor was $0.07 \mathrm{~m}$. For most objects, this region of inaccurate results actually extended beyond the sensor's minimum distance, in some cases up to $0.2 \mathrm{~m}$. At distances greater than this initial region of inaccurate detection, the sensor generally performed very well. It consistently and accurately detected the target objects, as represented by the large unshaded region in the center of table 1 . As the test distance approached the maximum distance of $3 \mathrm{~m}$, some objects were inaccurately detected or completely undetected.

Overall, the water jug and OSB were detected very well by the ultrasonic sensor. The metal fence post was detected only slightly less well. With the metal post, there was one test at $2 \mathrm{~m}$ with only intermittent detection. With the human model, there were incorrect detections up to $0.2 \mathrm{~m}$ (nearly three times the minimum distance), but the human model was detected consistently at distances equal to or greater than $0.3 \mathrm{~m}$. The wooden fence post was well detected up to $2.5 \mathrm{~m}$, after which point it was either intermittently detected or undetected in some tests. The Dracaena plant had results similar to those of the wooden fence post. Finally, detection of the juniper plant at distances greater than $2 \mathrm{~m}$ was slightly worse than that for the Dracaena plant. There was no detection of the juniper plant at $3 \mathrm{~m}$ and only one test with correct detection at $2.5 \mathrm{~m}$.

The ultrasonic sensor's detection ability for the dog model was considerably lower than that for the other target objects tested in this study. The sensor was completely una- 
ble to detect the dog model at distances of $2 \mathrm{~m}$ or greater. At less than $2 \mathrm{~m}$, it was able to detect the dog model in some tests; however, it only properly detected the dog model in every test at a distance of $0.4 \mathrm{~m}$. The detection of the dog model at the closest range resembled the detection results for the human model. As the distance decreased below $0.3 \mathrm{~m}$, the dog model was increasingly detected at incorrect distances. However, unlike the other objects tested, even at the closest distances $(0.025,0.075$, and $0.2 \mathrm{~m})$, the sensor indicated that no object was present in some tests. As mentioned earlier, ultrasonic sensors can have issues with the detection of soft or fluffy objects, as such surfaces absorb ultrasonic waves rather than reflect them. Thus, it is likely that the faux fur covering on the dog model contributed to the lower detection rates.

\section{Interference Testing}

The interference testing confirmed that the sensor always reported the distance to the closest object when multiple objects were in its field of view. In this testing, the Dracae$n a$ plant was placed at $0.1,1.5$, or $3 \mathrm{~m}$, and the human model was moved through all of the remaining accessible test locations. The sensor always detected whichever object (human model or plant) was closest to the sensor. Interference testing was also conducted by mounting the sensor on a trencher to see if mounting on mobile machinery had any effect on the sensor. However, as expected, the mounting did not have an effect on the sensor's ability to detect the human model. Many other interferences, such as machine vibration, wind, heat, humidity, and rain, could also have effects on the sensor's operation. These were not specifically tested in this experiment to limit the scope. Many of these interferences can be partially mitigated by design decisions, so engineers will need to consider them in any final application testing.

\section{Discussion}

In considering the results of the experiment, the ultrasonic sensor was best at detecting objects with a hard, reflective, compact surface area facing the sensor. Therefore, the target objects with hard surfaces, such as the water jug and OSB, were detected very well. The surface area of the water jug $\left(1000 \mathrm{~cm}^{2}\right)$ was actually less than that of the wooden fence post $\left(1292 \mathrm{~cm}^{2}\right)$; however, the water jug $(25 \mathrm{~cm}$ diameter, $40 \mathrm{~cm}$ height $)$ was more compact compared to the wooden fence post $(7.6 \mathrm{~cm}$ diameter, $170 \mathrm{~cm}$ height). The metal fence post had a smaller surface area than the wooden fence post. However, the structure of the metal fence post resembled that of a corner reflector, which made its reflections stronger than those from the wooden post. Objects with a soft, fluffy, or flexible surface were detected less reliably. Thus, the plants, with their flexible leaves, were detected less well than the more rigid target objects. The target object with the softest surface, the dog model covered in faux fur, was detected least reliably of all the objects.

The test results for the dog model warrant extra discussion, since its detection rate was so much lower than that of the other target objects. All other target objects were never undetected at distances less than $2 \mathrm{~m}$. The lack of detection for the dog model is a cause for concern, as it indicates that objects similar to the dog model could be completely missed by an ultrasonic sensor. This includes other animals with fur coats. In addition, vegetation can have a similar surface texture when the plants have very small thin leaves or when they are producing seed that is carried by the wind. This type of vegetative surface could also hide harder objects underneath. As mentioned in the Methods and Materials section, the surface of the dog model was created using faux fur fabric. When ob- 
tained for this experiment, this fabric was being sold for use in clothing. Therefore, it is possible that humans wearing such clothing could be detected with the low detection rates found with the dog model, rather than the better detection rates found with the human model. For reliable detection of an object similar to the dog model, an array of multiple ultrasonic sensors, ensuring that at least one sensor is the appropriate distance from the object for good detection, would be required. Another option is the use of arrays of complimentary sensors of different types.

\section{Conclusion}

The objective of this study was to ascertain the ability of an ultrasonic sensor to accurately detect objects commonly found in outdoor agricultural and construction environments. This information should help inform engineers as they make decisions on the use of ultrasonic sensors for given detection tasks. However, the applicability of an ultrasonic sensor in these environments is entirely dependent on how the sensor will be used. If the sensor will be used to detect large rigid objects, such as buildings and other vehicles for obstacle avoidance in clear fields, an ultrasonic sensor will likely work well. However, if the goal is to detect animals with fur coats or humans who could wear similar fur-like clothing, an ultrasonic sensor would be poorly suited. Other applications, such as obstacle detection on a vehicle traveling through tall grass prairie, could be complicated by the ultrasonic sensor's inability to distinguish between large plants and other objects. As attested to by the wide variety of research projects that use ultrasonic sensors in various systems, ultrasonic sensors have a definite role to play in improving agricultural systems. However, as these projects exit the realm of research and begin to be implemented in production systems, it will be necessary to consider how to account for the way the sensors respond to the target objects discussed.

\section{Acknowledgements}

This work was funded with the support of Charles Machine Works, Inc., Perry, Oklahoma.

\section{References}

Andújar, D., Escolà, A., Dorado, J., \& Fernández-Quintanilla, C. (2011). Weed discrimination using ultrasonic sensors. Weed Res., 51(6), 543-547. http://dx.doi.org/10.1111/j.13653180.2011.00876.x

Aziz, S. A., Steward, B. L., Birrell, S. J., Kaspar, T. C., \& Shrestha, D. S. (2004). Ultrasonic sensing for corn plant canopy characterization. ASABE Paper No. 041120. St. Joseph, Mich.: ASABE.

Buck, N. L. (1991). Human presence detection by a capacitive proximity sensor. Appl. Eng. Agric., 7(1), 55-60. http://dx.doi.org/10.13031/2013.26191

Doerr, Z., Mohsenimanesh, A., Laguë, C., \& McLaughlin, N. B. (2013). Application of the LIDAR technology for obstacle detection during the operation of agricultural vehicles. Canadian Biosyst. Eng., 55, 2.9-2.16. http://dx.doi.org/10.7451/CBE.2013.55.2.9

Escolà, A., Planas, S., Rosell, J. R., Pomar, J., Camp, F., Solanelles, F., Gracia, F., Llorens, J., \& Gil, E. (2011). Performance of an ultrasonic ranging sensor in apple tree canopies. Sensors, 11(3), 2459-2477. http://dx.doi.org/10.3390/s110302459

Guo, L., Zhang, Q., \& Han, S. (2002). Agricultural machinery safety alert system using ultrasonic sensors. J. Agric. Saf. Health, 8(4), 385-396. http://dx.doi.org/10.13031/2013.10219

Jeon, H. Y., Zhu, H., Derksen, R., Ozkan, E., \& Krause, C. (2011). Evaluation of ultrasonic sensor for variable-rate spray applications. Comput. Electron. Agric., 75(1), 213-221. 
http://dx.doi.org/10.1016/j.compag.2010.11.007

Keicher, R., \& Seufert, H. (2000). Automatic guidance for agricultural vehicles in Europe. Comput. Electron. Agric., 25(1-2), 169-194. http://dx.doi.org/10.1016/S0168-1699(99)00062-9.

Kise, M., Zhang, Q., \& Noguchi, N. (2005). An obstacle identification algorithm for a laser range finder-based obstacle detector. Trans. ASAE, 48(3), 1269-1278. http://dx.doi.org/10.13031/2013.18491

Leidenfrost, H. T., Tate, T. T., Canning, J. R., Anderson, M. J., Soule, T., Edwards, D. B., \& Frenzel, J. F. (2013). Autonomous navigation of forest trails by an industrial-size robot. Trans. ASABE, 56(4), 1273-1290. http://dx.doi.org/10.13031/trans.56.9684

Massa, D. P. (1999). Choosing an ultrasonic sensor for proximity or distance measurement: Part 2. Optimizing sensor selection. Sensors Online. Retrieved from www.sensorsmag.com/sensors/ acoustic-ultrasound/choosing-ultrasonic-sensor-proximity-or-distance-measurement-838

O'Sullivan, J. A. (1986). Evaluation of a polaroid ultrasonic proximity transducer. J. Agric. Eng. Res., 34(1), 63-73. http://dx.doi.org/10.1016/S0021-8634(86)80014-2

Shirley, P. A. (1989). An introduction to ultrasonic sensing. Sensors, 6(11), 10-17.

Shutske, J. M., Gilbert, W., \& Chaplin, J. (2001). Evaluation of a microwave and infrared humanpresence sensing system for agricultural equipment. J. Agric. Saf. Health, 7(4), 253-64.

Steen, K. A., Villa-Henriksen, A., Therkildsen, O. R., \& Green, O. (2012). Automatic detection of animals in mowing operations using thermal cameras. Sensors, 12(6), 7587-7597. http://dx.doi.org/10.3390/s120607587

Turner, J. D., \& Austin, L. (2000). Sensors for automotive telematics. Meas. Sci. Tech., 11(2), R58R79.

Venem, M. T., Shutske, J. M., \& Gilbert, W. J. (2006). Testing and creation of a safety system to disengage the PTO of a tractor. Appl. Eng. Agric., 22(1), 5-12.

Wei, J., Rovira-Mas, F., Reid, J. F., \& Han, S. (2005). Obstacle detection using stereo vision to enhance safety of autonomous machines. Trans. ASAE, 48(6), 2389-2397. http://dx.doi.org/10.13031/2013.20078

Yang, L., \& Noguchi, N. (2012). Human detection for a robot tractor using omni-directional stereo vision. Comput. Electron. Agric., 89, 116-125. http://dx.doi.org/10.1016/j.compag.2012.08.011 